\title{
Um mito tupi traduzido por Giuseppe Ungaretti:
}

"Mai Pituna Oiuquau Ãna"

\section{("Como a Noite Apareceu")}

“Portanto, o primeiro modo de conhecer do homem é a poesia: é seu modo inato de ter noção daquilo que, em sua natureza, permanece imortal [...]. No princípio a palavra era, para o homem, poesia $[. .]$.$" (1).$ 

Lendas Índias do Gênesis, inauguram uma série de traduções brasileiras que Ungaretti publicou pela primeira vez na revista italiana Poesia(2). As traduções deviam integrar um livro de Ungaretti sobre o Brasil, que nunca

foi terminado - como explica o poeta nas primeiras linhas de introdução à breve antologia - porque a repentina volta à Itália, em 1942, por ocasião da guerra, determinou a suspensão da busca de material.

A primeira das lendas índias do Gênesis é o mito tupi "Mai Pituna Oiuquau Ãna" (“Como a Noite Apareceu”), que Ungaretti traduziu para o italiano a partir da tradução interlinear em português de Couto de Magalhães, que por sua vez traduziu a partir da versão oral tupi, que é o primeiro a transcrever, em seu O Selvagem (3).

O mito conta que no princípio era sempre dia, e a noite dormia no fundo das águas, domínio da Cobra Grande. A filha da Cobra Grande casa-se com um jovem índio, mas se recusa a dormir com o marido se ele não mandar buscar a noite no rio. Três "fâmulos" são enviados à Cobra Grande, que lhes entrega a noite fechada num caroço de tucumã, advertindo-os de que não devem abri-lo. Dele provêm os cantos noturnos dos grilos e dos sapinhos, e os três índios não resistem à tentação de abrir o caroço. De repente a noite cai, tudo escurece, e o piloto do barco exclama: “Nos perdemos!". Então todas as coisas do bosque transformam-se em animais, e a canoa se torna em parte onça e em parte pato. Finalmente aparece Vênus, a última estrela da noite, e só então a filha da Cobra Grande separa o dia da noite e transforma alguns (não se sabe bem quem) em cujubim e inambu (duas aves cujo canto se distingue de todos os outros, como explica Ungaretti numa nota), e os fâmulos em macacos.

A tradução de Ungaretti segue quase pontualmente a tradução interlinear de Magalhães. Por motivos óbvios, Ungaretti coloca na ordem normal (em italiano) as preposições (que Magalhães deixara na ordem original tupi, por motivos didáticos, pois os textos das lendas são parte integrante de seu curso de língua tupi), mas compensa essa variação transportando todos os verbos para o final das frases, um artífício que causa um estranhamento comparável àquele produzido pela disposição incomum das preposições no texto de Magalhães. O tom hierático e sentencioso da tradução é dado por tais inversões da ordem do período, pelo uso de iterações, paralelismos, anáforas, e pela elegância e simplicidade do léxico. O efeito de lentidão, produzido pela combinação de vários artifícios, evoca o clima quase ritual onde se dão as reações dos homens diante dos eventos primordiais.

A interpretação do mito que Ungaretti oferece nas notas à tradução pode servir para definir em que medida a escolha e a tradução desse mito se inserem no curso das pesquisas - sobretudo poéticas - que ocupavam Ungaretti naqueles anos.

O título Favole Indie della Genesi, que Ungaretti dá em bloco aos três mitos, é obviamente inspirado na interpretação do próprio Magalhães (que, no entanto, se refere exclusivamente à primeira lenda). De acordo com Magalhães, a lenda é "provavelmente um fragmento do Genêsis dos antigos selvagens sul-americanos", e é evidente sua analogia com a história bíblica de Adão e Eva e com os Vedas: o paraíso é perdido por causa de uma desobediência, mais precisamente do pecado da curiosidade a respeito de uma fruta proibida.

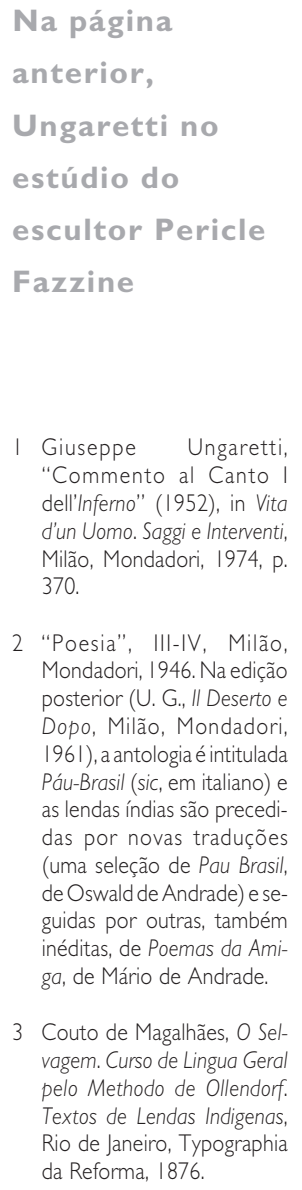


Em suas notas à tradução, Ungaretti não faz qualquer alusão a essa analogia; pelo contrário, previne o leitor (a propósito da autenticidade do mito em geral) da possibilidade de que os próprios narradores tupis tenham introduzido "melhorias", sob a influência de trezentos anos de catequização jesuíta. Por outro lado, insiste nas qualidades poéticas do texto e nos temas que o atraem: a noite que "obriga [as coisas] ao esforço de voltar à luz”, o “distanciamento de sonho", e ainda "o renascer da luz" (4).

A idéia de voltar à luz, da revelação das coisas, em contraposição à noite, é reforçada, na tradução de Ungaretti, por uma transformação lexical importante: a exclamação de surpresa do piloto, quando a noite cai repentinamente: "Nos perdemos!", que Ungaretti traduz por "Agora desapareceremos". Limitando o campo semântico de "perder-se" em favor da dimensão sensorial de "desaparecer" (porque as coisas desaparecem diante da vista), a tradução remete mais precisamente, por oposição à absoluta escuridão da noite, ao renascer das coisas diante da vista.

Estudos recentes de M. Petrucciani (5) demonstraram a "freqüência majoritária" com a qual o poeta privilegia a primeira fase dos ciclos temporais da vida do homem, do dia, do ano: o nascimento, a aurora, a primavera. A análise de Petrucciani começa pelos manuscritos inéditos do período das aulas universitárias brasileiras, demonstrando também que é esse o momento em que Ungaretti começa a sistematizar teoricamente uma série de intuições e reflexões sobre o significado da imagem inicial, da aurora, que terá sua máxima expressão na Canzone de abertura da Terra Promessa. À luz desses estudos de Petrucciani, e particularmente dos manuscritos brasileiros, até hoje inéditos, é evidente a coincidência do argumento da lenda tupi com os temas que Ungaretti estava elaborando no mesmo período, e que serão centrais em sua poesia posterior.

É sobretudo o primeiro manuscrito analisado por Petrucciani, ou seja, o texto datado "Poços de Caldas, 6/11/1940", dedicado ao primeiro canto do Inferno de Dante, a oferecer os elementos que confirmam que o “pensamento dominante" de Ungaretti nesse período é exatamente "a aurora, o nascer da aurora, a transmutação da noite em dia, da escuridão em luz: e depois a progressiva, cada vez mais nítida, percepção do espaço" (6). Mas quais são as primeiras coisas que renascem diante da vista no mito tupi? Cronologicamente, parece que a transformação da canoa em onça e em pato acontece durante a noite, mas as imagens da transformação são claramente desenhadas para o olho do ouvinte (e, em seguida, do leitor): "Do paneiro gerou-se a onça; o pescador e sua canôa se transformarão em pato; de sua cabeça nascerão a cabeça e o bico do pato; da canôa o corpo do pato; dos remos as pernas do pato" (7). As primeiras imagens que se oferecem à imaginação (se não à vista) são portanto dedicadas a essa extraordinária transformação, que constitui a "bestialização" de um objeto. Seguirão, logo em seguida, as "bestializações" de alguns índios em aves e de outros em macacos.

Encontramos aqui uma primeira coincidência com as reflexões contidas no manuscrito citado, o texto sobre o primeiro canto do Inferno. Petrucciani refere que, na primeira parte do manuscrito, Ungaretti concentra-se nas três feras encontradas por Dante, e conclui: "As três feras, a bestialidade humana: mas quando o homem toma conhecimento do seu próprio estado de bestialidade, então começa a tentar sair dele, para vencer o caos e humanizar-se [...]" (8). Petrucciani identifica portanto na primeira parte do manuscrito um movimento que define "bestialidade vs. humanização". No mito traduzido por Ungaretti trata-se do movimento contrário, "humanização $v s$. bestialidade", mas evidentemente os dois movimentos levam a conclusões análogas: a tomada de consciência do estado de bestialidade conduz o homem à humanização.

O segundo movimento das reflexões de Ungaretti sobre o canto I do Inferno, no manuscrito citado, sempre de acordo com Petrucciani, é o movimento noite vs. aurora, que se liga profundamente ao terceiro: sono vs. despertar da consciência. No mito, o movimento passa por duas fases: dia $v s$. 
noite $v s$. primeira aurora. A analogia com a leitura ungarettiana do canto do Inferno pode se observar na relação entre o primeiro e o segundo movimento: a noite - ainda mais na ocasião mítica de sua criação - é seguida pelo nascer do dia, que transforma as coisas diante dos olhos dos personagens. É o primeiro dia depois da primeira noite, a primeira aurora, o primeiro despertar da consciência. É verdade que a primeira aurora é marcada pela degradação ao estado animal (ou seja, pela perda da consciência) de alguns indivíduos, mas a conseqüiência mais importante da segunda parte do mito diz respeito a toda a comunidade: trata-se da aquisição da consciência humana da passagem da noite para o dia para a noite, do nada para o despertar para o nada. Em outras palavras, do mistério do passar do tempo.

Em 1932, Ungaretti começara a escrever a Canzone, composição de abertura da Terra Promessa (9). Na produção do período entre 1932 e 1950 (ou seja, até a publicação da Terra Promessa), encontramos os sinais do esforço constante de amadurecimento do mesmo tema da passagem noite/aurora, que será o tema central da Canzone. Esse momento que Ungaretti encontra em Dante já estava no centro do pensamento de Ungaretti leitor de Leopardi. Na segunda conferência sobre Vico, pronunciada em São Paulo (1937), Ungaretti comentava o Tramonto della Luna (Pôr da Lua) de Leopardi, nos seguintes termos: “Há no poema uma grande pausa cósmica: aquele momento em que, tendo já se posto a lua, ainda não surgiu o sol: é um momento de suspensão espantosa, e depois, naturalmente, poeticamente, tudo se renova: ao indivíduo com um pé na cova, sucede o filho; as novas gerações sucedem às velhas [...] e enfim, depois do pôr da lua, surgira aquela noite uma aurora de um furor inaudito" (10).

Anos depois, citando o mesmo poema de Leopardi a propósito da sua Canzone, o próprio Ungaretti chama a atenção do leitor para a relação entre os dois poemas:

“Há um momento no Tramonto della Luna de Leopardi em que não há mais nenhuma luz, não há luz do sol, que ainda não chegou nem foi anunciada, não há mais a luz da lua, que se pôs [...]. É um mundo completamente obscuro, vazio. É um momento de silêncio, apocalíptico, do fim de tudo, do fim real de tudo, é o nada, e é apenas o momento em que dia e noite parecem desaparecer, e é apenas um simples momento de interrupção e espera” (11).

Em ambas as interpretações do Tramonto della Luna, Ungaretti salienta o momento "apocalíttico", de "suspensão espantosa", da noite como metáfora da morte, mas também como “espera”, ou seja, como prenúncio do renascer, no ciclo perene da vida do homem e da Terra.

Num poema de 1918 (na coletânea L'Allegria), encontramos um momento muito parecido, o despertar do ano, acompanhado por um "infinito cansaço": "Si porta. Si portal l'infinita stanchezza/ dello sforzol occulto/ di questo principiol che ogni anno/ scatena la terra" ("Se leva. Se leva/o infinito cansaço/ do esforço/ oculto/ deste princípio/ que todo ano/ a terra desencadeia").

O "esforço oculto" (o adjetivo "oculto", acentuado pelo isolamento do verso, pertence ao campo semântico da noite) está oculto na terra, onde se prepara, no inverno, longe da vista, o despertar da primavera. Também na Canzone (cujo tema é o nascer do dia), o despertar é acompanhado por um cansaço, e mais precisamente por uma "quiete stanca" ("quietude fatigada"). A associação entre os dois poemas é ainda mais clara quando se leva em conta o comentário de Ungaretti - explicação dessa mesma estrofe (12) -, no qual lembra auroras vistas em tempo de guerra: "Estive na guerra, onde agonia e morte eram constantes, e assisti por muitos dias, e acabaram sendo anos, a diversos começos do dia, a diversas auroras [...]" (13). A "quietude fatigada", escrevia ele poucas linhas antes, é a "quietude dos dois quartetos precedentes, nos quais se via a vida desaparecer, o nada substituir a vida". O "infinito cansaço" da aurora, no poema escrito durante a guerra, só pode ser o mesmo.
G. Ungaretti, LaTerraPromessa, Vita d'un Uomo, Tutte Poesie, Milão, Mondadori 1969

10 Idem, "Influenza di Vico sulle Teorie Estetiche d'Oggi", in Vita d'un Uomo, Saggi Interventi, op. cit., p. 35I.

II Idem, Note a LaTerraPromessa, in Vita d'un Uomo, Tutte le Poesie, op. cit., p. 550. Cf. com os versos da Canzone: "So, utima metamorfosi dell'auroral Oramai so che il filo dello trama/ Umana, pare rompersi in quell'ora".

12 Eis a estrofe inteira: "Tutto si sporse poi, entro trasparenze, Nell'ora credula, quando, la quiete/ Stanca, da dissepolte arborescenze/ Riestesas misura delle mete,/ Estenuandosi in iridi echi, amore/ Dall'aereo greto trasali sorpreso/ Roseo facendo il buio e, in quel colore, / Più d'ogni vito un arco, il sonno, teso" (Canzone, vv. 9-16)

I 3 Idem, Note a La Terra Promessa, op. cit., p. 556 
I 4 Idem, Favole Indie della Genesi. Come si Fece Notte, op. cit., p. 191 (em nota).

I 5 Idem, Dialogo (1966-1968), Vita d'un Uomo, Tutte le Poesie. op. cit.

16 O texto fundamental é precisamente Note a La Terra Promessa, op. cit., pp. 545-67.

17 C. Ossola, Giuseppe Ungaretti op. cit., pp. 385-6.

18 G. Ungaretti, Note a La Terro

19 Idem, ibidem, p. 556.

20 Idem, Favole Indie della Genesi, Come si Fece Notte, op. cit., p. 191 .

\section{Corpo docente \\ da Universidade \\ de São Paulo, do \\ qual fazia parte \\ o escritor \\ italiano} Promessa, op. cit., pp. 556-7.

O olho do poeta é atraído sobretudo por uma imagem, que define de "malincônico debussysmo", o caroço de tucumã que contém os cantos noturnos dos grilos e dos sapinhos, ou seja, "oinfinito chiassodella sera" ("o infinito barulho da noite"), como escreve Ungaretti nas notas (14). Na noite do campo ou do bosque, longe da luz artificial, a vista revela-se impotente e o mundo é percebido apenas pelo ouvido: é a sensação oferecida pelo caroço de tucumã que fascina os fâmulos e os induz à transgressão.

Ungaretti reforça, na tradução, a sinestesia já presente no original: “O que é este barulho? Vamos ver?", reunindo os dois termos no breve verso "Il chiasso vediamo" ("Vejamos o barulho"). A sinestesia, em termos quase idênticos, é retomada por Ungaretti num poema de amor, La Conchiglia (15): “D'un tremito il tuo cuore ammutirebbe/Se poi quel chiasso/ Dagli echi generato, tu scrutassi/Insieme al tuo spavento nell'udirlo" ("Num tremor teu coração emudeceria/ Se aquele barulho/ Gerado pelos ecos, perscrutasses/ Junto ao teu espanto em ouvi-lo"). O caroço de tucumã que continha o "barulho" tornouse uma "conchiglia del buio" ("concha da escuridão"), que anuncia à amante a lembrança de Ungaretti “Già divenuto spettro/ In un non lontano futuro" ("Que já se tor-

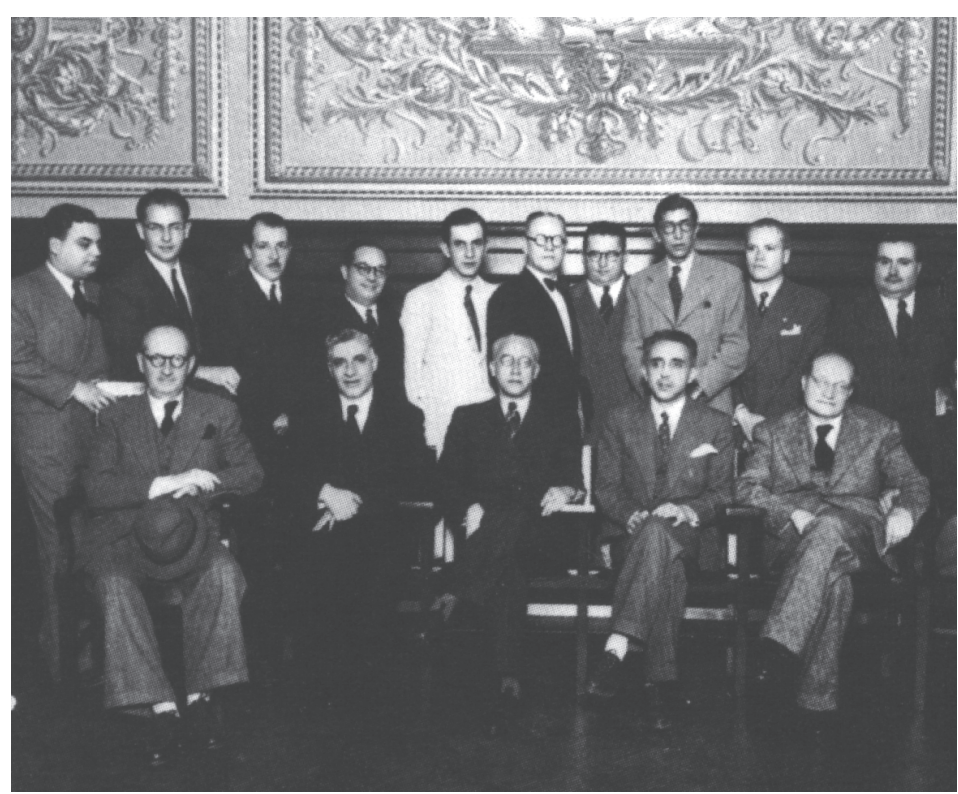

nou fantasma/ Em um futuro não longínquo"). Os barulhos da noite remetem aos ecos da memória, trâmites de um conhecimento imperfeito, cujas modalidades e cujos limites são o objeto do poema.

O próprio Ungaretti já salientou a origem platônica de sua visão poética (16); no que diz respeito à relação entre esta e a tradução do mito, Carlo Ossola escreveu páginas esclarecedoras (17), exatamente a partir do verso citado: "Il chiasso vediamo", individuando sua analogia com o verso da Canzone: "estenuandosi in iridi echi" ("estenuando-se em ecos iridescentes"). Ossola cita a esse propósito um trecho das Notas à Terra Promessa: "Estenuando-se em ecos iridescentes [...] O conhecimento que tem o poeta da realidade ideal é um conhecimento obtido através de ecos, ele não tem um conhecimento direto, porque conhecemos a realidade apenas por trâmites; conhecemos a realidade material até um certo ponto, mas a verdadeira realidade só conhecemos através de ecos, cujo símbolo sensível é oferecido pelo nascer do dia". "Estenuando-se em ecos iridescentes", ou seja, enquanto os ecos consumiam-se em iridescências. Então, por analogia, passo de uma imagem auditiva a uma imagem visual (18).

O barulho visível da tradução da lenda tupi assim como os ecos visíveis da Canzone são filtros do conhecimento. A idéia do "nascer do dia [...] em seu silêncio cheio de vozes, de vozes que parecem ecos de vozes" (19) evoca o sentido de "distanciamento, distanciamento de sonho" (20) inspirado ao poeta pela imagem do caroço de tucumã do qual provêm os cantos dos grilos e dos sapinhos. Uma sensação de distanciamento resultante da parcial cegueira que aflige o homem do mito platônico da caverna, cegueira que lhe permite, uma vez que saiu da caverna, ver inicialmente apenas sombras, e depois, cada vez melhor, as imagens, como que refletidas nas águas. Ecos, reflexos, sombras, são nosso modo de conhecer a realidade, da qual estamos separados por "uma infinita ramificação de muros que o tempo coloca diante da 'primeira imagem', para torná-la cada vez mais 
distante de nós" (21). Mas depois de toda noite, de todo "estado de escuridão", surge a aurora; e a cada início renasce a possibilidade de que se cumpram as palavras conclusivas do mito da caverna: "Enfim, creio eu, aquele homem poderá observar e contemplar o que é realmente o sol" (22). Mesmo que apenas por um instante, como pensa Ungaretti: "Acontece, de fato, que por iluminação, por lampejos, se consiga romper esta infinidade de muros, e que em algum sentido se tenha não apenas o eco da idéia, mas se conheça a própria idéia" (23).

\section{Como a Noite Apareceu}

\section{(Mai pituna Oiuquau Ãna)}

(Versão do tupi de Couto de Magalhães. A tradução de Ungaretti é baseada na tradução interlinear; esta é a tradução livre.)

"Os vassalos foram-se, ouviram barulho dentro do caroço de tucumã: ten, ten, ten; ten, ten, ten. Era o barulho dos grilos, e dos sapinhos com eles, que cantam durante a noite. Quando os vassallos estavam já longe, um deles disse aos seus companheiros: 'O que é este barulho? Vamos ver?' O piloto disse: 'Não; do contrário nos perderemos. Remai, vamos embora'. Eles se foram. Eles estavam ouvindo o barulho; não sabiam o que era aquele barulho. Eles estavam já muitíssimo longe quando ajuntaram-se no meio da canôa para abrir o caroço de tucumã, para ver o que estava dentro dele. Um acendeu fogo; derreteram o breu que estava fechando a porta do caroço do tucumã. Quando eles abriram, repentinamente noite densa já! Então o piloto disse: 'Nos perdemos!... A moça, em sua casa, já sabe que nós abrimos este caroço de tucumã'. Seguiram viagem. A moça, em sua casa, disse a seu marido: 'Eles soltaram a noite. Agora vamos esperar a manhã'. Então todas as coisas que estavam espalhadas pelo bosque metamorfosearam-se em animaes, em pássaros. Todas as coisas que estavam espalhadas pelo rio metamorfosearam-se em patos, em peixes; o paneiro virou-se em onça. O pescador virou-se, com sua canôa, em pato; sua cabeça em cabeça de pato; seu remo virou em pernas de pato; a canôa em corpo de pato. Quando a filha da Cobra Grande viu a estrela Venus, disse a seu marido: 'Manhã está vindo; eu vou dividir a noite do dia'."

\section{Come Si Fece Notte}

(Tradução do português de Giuseppe Ungaretti)

\section{“Dalla noce chiasso d'udiva:}

'Tem, ten, ten...xi...'.

I famigli dalla noce

Grilli e ranocchi udivano.

Quando i famigli lontani furono, dissero:

'Il chiasso vediamo'.

Il piloto disse:

'Non aprite,

Se no, spariremo;

\section{Remate'.}

Ifamigli remarono.

Dalla noce di tucumano

Sempre chiasso s'udiva.

Lapece che il nòcciolo chiudeva, daifamigli [fu sciolta.

Le cose scure divennero.

Il piloto disse:

'Ora spariremo;

La giovane sotto il suo tetto sa che il nòcciolo dai famigli fu aperto'.

Lo sposo disse:

'La notte è libera'.

La sposa disse:

'Il nascere del giorno aspetta'.

Le cose del bosco, animali e uccelli

[divennero.

Il sedile della canoa, il giaguaro generò . la prua, testa e becco dell'anitra fu.

La pancia della canoa, il corpo dell'anitra

[fu.

Le zampe dell'anitra, i remi furono.

La stella allora luccicò.

La figlia del Cobra Grande disse:

' $L$ 'alba si rompe;

la notte dal giorno, divido'."

(Os versos selecionados são a parte central do mito, onde se descreve a primeira noite da humanidade.)
2 I Idem, Note a La TerraPromessa, op. cit., p. 560

22 Cit. por M. Petrucciani, em "L'Idea Come Memoria, la Poesia Come Inizio", op. cit. p. 25

23 G. Ungaretti, Note a La Terra Promessa, op. cit., p. 561 